
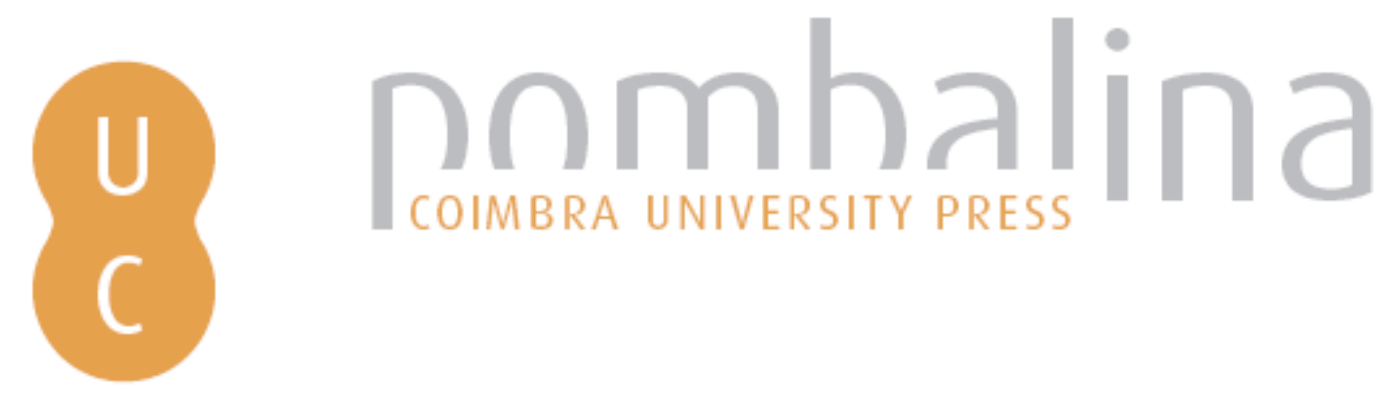

\title{
A cinza falante do poeta: na celebração dos 1900 anos da morte de Marcial
}
Autor(es):
Medeiros, Walter de
Instituto de Estudos Clássicos, Centro de Estudos Clássicos e
Publicado por:
Humanísticos; Departamento de Estudos Clássicos, Centro de Estudos Clássicos

\author{
URL \\ persistente: \\ URI:http://hdl.handle.net/10316.2/34627 \\ DOI: \\ DOI:http://dx.doi.org/10.14195/978-989-26-0901-0_1
}

Accessed : $\quad$ 26-Apr-2023 13:48:13

A navegação consulta e descarregamento dos títulos inseridos nas Bibliotecas Digitais UC Digitalis, UC Pombalina e UC Impactum, pressupõem a aceitação plena e sem reservas dos Termos e Condições de Uso destas Bibliotecas Digitais, disponíveis em https://digitalis.uc.pt/pt-pt/termos.

Conforme exposto nos referidos Termos e Condições de Uso, o descarregamento de títulos de acesso restrito requer uma licença válida de autorização devendo o utilizador aceder ao(s) documento(s) a partir de um endereço de IP da instituição detentora da supramencionada licença.

Ao utilizador é apenas permitido o descarregamento para uso pessoal, pelo que o emprego do(s) título(s) descarregado(s) para outro fim, designadamente comercial, carece de autorização do respetivo autor ou editor da obra.

Na medida em que todas as obras da UC Digitalis se encontram protegidas pelo Código do Direito de Autor e Direitos Conexos e demais legislação aplicável, toda a cópia, parcial ou total, deste documento, nos casos em que é legalmente admitida, deverá conter ou fazer-se acompanhar por este aviso.

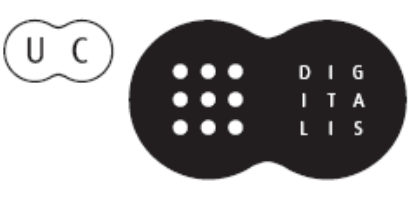




\section{Toto notus in orbe Martialis}

\section{Celebração de Marcial \\ 1900 anos após a sua morte}

Coordenação

Cristina de Sousa Pimentel

Delfim F. Leão

José Luís L. Brandão

Instituto de Estudos Clássicos

Centro de Estudos Clássicos e Humanísticos

UNIVERSIDADE DE COIMBRA
Departamentō de Estudos Clássicos Centro de Estudos Clássicos UNIVERSIDADE DE LISBOA 


\title{
A CINZA FALANTE DO POETA NA CELEBRAÇÃO DOS 1900 ANOS DA MORTE DE MARCIAL
}

WALTER DE MEDEIROS

Universidade de Coimbra

\begin{abstract}
Martial's ashes - that, according to the text, are supposed to have been cast to the Tagus river, near Bilbilis - recall some parts of the poet's life, which, after thirty four years spent in Rome, returned back to his birth place, disenchanted and missing the Urbs that had so much inspired the best of all his poetry.
\end{abstract}

Um punhado de cinzas sobre o rio. Quem as lançou? Aquele monte, de encanecido, nem lágrimas tem para chorar. O prado, o bosque rescendem ao orvalho da manhã, mas só nas raízes circula o viço da primavera.

As cinzas caem, formam um grumo, outro grumo, tentam - canseira vã - resistir ao assalto das águas. E cada grumo, ao delongar-se, cava um soluço indefinível, átomo do nada que irá perder-se no coração do mar.

Um punhado de cinzas sobre o rio. Quem as lançou? Talvez um amigo, aquele Instâncio Rufo, contado entre os mais fiéis e verdadeiros, a quem o poeta dedica o último dos seus epigramas. ${ }^{1}$ Rufo, para mais, conhecia o drama de uma alma que buscava o amor e o não encontrou. ${ }^{2}$

Um punhado de cinzas sobre o rio. Quem as lançou? O ideal seria Marcela, a amiga incorrupta que lhe faltou em Roma; e que, no regresso

1 12.98. Serviria, nesta ficção, Terêncio Prisco, a quem Marcial dedica a carta-prefácio do 1.12 (e outras composições do mesmo livro: 3, 14, 62, 92). Mas cf. n. 2.

28.73 (em que M. confessa a sua «incapacidade de amar»). 
melancólico à Hispânia, o confortava com a pureza da dicção vernácula. ${ }^{3}$ Marcela fora generosa com o poeta: ofereceu-lhe casa e quinta, com dosséis, rosais, arrulho de pombas, o defluir manselinho das fontes em jardins mais belos que os de Alcínoo. ${ }^{4} \mathrm{O}$ ideal! O ideal, para os poetas, agoniza, como a Quimera trespassada pela lança do herói. Mas seja Marcela o ideal, seja de outrem o braço que lançou as cinzas sobre o rio. Lançou: e de pronto o recolheu, com o pudor dos sentimentos que se querem velados pela sombra. A sombra maior de todas - porque é feita para não descontinuar.

Na última inflexão da vida sobre a terra, a cinza ainda reteve, no monte, o perfil de seu pai: era Frontão, de nome e de memória, por aquele cenho achatado e casmurro no exterior, quando por dentro era um lago de mansidão. A mãe, não era preciso identificá-la: estava derredor, naquele bosque, naquele prado húmido e compassivo; tinha-lhe ficado o nome de Flacila, 'a Almofadinha', porque sabia, no jeito mimoso, agasalhar medrosos e aflitos. ${ }^{5}$ Ora pai e mãe entressonhavam os êxitos do filho nas tribunas do Foro, Cícero redivivo a inflamar as turbas, mas a conservar incólume a garganta. Por esse tempo, e à parte o discurso pelas melhores escolas da Hispânia, o moço não embarcava ainda nessas viagens dos pais, embebido na cavaqueira com os amigos, enlevado na madracice das sestas, ou, ao invés, despedido como flecha nas montarias, solerte em espreitar as faunesas que se banhavam, vespertinas e desnudas, nas ansas do rio.

Mas os anos vão, os anos vêm, as brancas floriam na fronte larga de seu pai, e a mãe bem se queixava das cruzes que lhe doíam e do coração que se ofuscava em trepar aos morros altaneiros. Até que, em seroada à lareira, o vílico falou - e a sua fala venceu as últimas delongas: «Este rapaz bebeu do melhor que há nas escolas da província. Mas por cá não governa fama nem dinheiro. É tempo de brilhar no grande Foro, antes que um dia the chegue o tropeço dos anos. Roma, Roma está à sua espera. E não lhe faltam por lá devotos da nossa terra.» Frontão ainda carranqueou: um vílico a trinchar problemas na casa do senhor? Mas todos os votos congruíam: por isso nem redarguiu; e pôs-se a fazer contas

\footnotetext{
312.21 .

412.31 .

55.34 .
} 
pelos dedos. A mãe (são lances previsíveis) ainda choramingou. O moço, esse sentia agora o deslumbramento de um sonho bem sonhado: ia viver a sua parcela da Vrbs maxima, a tentação suprema da glória, do poder, da riqueza; o sortilégio (quem sabe?) do amor e do prazer. Adeus, monte; adeus, prados; adeus, rio! Adeus, família, amigos, faunesas de outras eras! O moço vai partir, por muitos anos. Com saudades, já se sabe, de voltar. Mas no tarde será, quando entre vida e morte for estreita a película que as separa.

O espectáculo era assim, quando a nave aportou. Chamas coleantes, turbilhões de fumo envolviam palácios e templos, edifícios públicos e privados, casas modestas e choupanas. A cinza era mortalha de tudo o que cobria. Derrocava a cidade de mármore que Augusto se gloriava de deixar. Pobre caducidade da humana geração! A cinza imposta como lepra dos lauréis.

O fogo poupou alguns palácios majestosos; outros foram logo reconstruídos, à custa do trabalho escravo, e com esplendor ainda maior. Ao jovem recém-chegado, de honesta família, abriram as suas portas os Sénecas e os Pisões, hispanos como ele; ${ }^{6}$ e um mecenato glorioso dispensou da advocacia quem da advocacia não queria viver. ${ }^{7}$ Verdade seja que de onde em onde a consciência o acusava ou um amigo rigoroso (Quintiliano, por exemplo) $)^{8}$ - mas o poeta preferia gozar a vida, antes que fosse tarde. ${ }^{9}$ Não a gozava, a bem dizer, como desejaria, porque os amigos nem sempre estavam disponíveis; mas entesourava, dia após dia, observações sobre uma cidade, uma sociedade que breve conheceria como as palmas das mãos.

Aquela prosperidade descuidosa ruiu, quando ruíram as casas dos Pisões e dos Sénecas, implicados na conjura contra Nero. O lado negro de Roma descobria a sua face, e a existência do poeta entrou em fase crepuscular. Em casa dos seus protectores conhecera gente importante que lhe poderia valer. Não valeu. Gente que, à parte os amigos verdadeiros, lhe oferecia, quando muito, em troca de uma diária vassalagem, a espórtula

\footnotetext{
${ }^{6} 4.40 ; 12.36$.

72.30 .

82.90 .

9 ibidem.
} 
de cem quadrantes. ${ }^{10} \mathrm{~A}$ flama poética (que vinha dos verdes anos) levou-o a publicar três livros - De spectaculis, Xenia e Apophoreta -, acolhidos com favorável audiência. Os entendidos perceberam que, a despeito da frivolidade dos temas, a elegância e a concisão dos dísticos requeriam muito trabalho de lima. Ao cabo de alguns anos amargos, Tito concedeu ao poeta o ius trium liberorum, privilégio que seu irmão, Domiciano, havia de confirmar. ${ }^{11}$ Mas por aqui se ficaria a munificência do príncipe, repetidas vezes adulado: ao dominus et deus não sorriria muito aquele vate pedinchão que bosquejava tantos quadros negativos da sua Roma felix.

Para mais, os epigramas que Marcial escrevia e eram recitados com aplauso em banquetes, em festas, em reuniões, começaram a ser pilhados por versejadores sem talento que, deste modo, procuravam ascender à fama e à notoriedade. ${ }^{12}$ Pior, quando serviam para atribuir ao poeta os ataques nominais que ele nunca divulgaria. ${ }^{13} \mathrm{O}$ remédio era publicar as suas composições, para garantir, desta sorte, a genuinidade da origem. Único benefício, aliás, que Marcial poderia esperar, já que, na ausência de direitos de autor, o livreiro embolsava todos os proveitos da edição.

Nascem, assim, os doze livros dos Epigrammata, publicados, com algumas intercadências de desalento, ao ritmo de um volume por ano. A fama do poeta ultrapassa as fronteiras do Lácio e dos Alpes, alarga-se a vários pontos do Império, mas Marcial continua a vestir togas coçadas e a morar no quarto rumoroso de um prédio-colmeia. Verdade seja que chegou a ter casa própria em Roma e uma quinta acanhada na via Nomentana. ${ }^{14}$ - mas teve de recorrer a Plínio-o-Moço para pagar a viagem de regresso à Hispânia.

Os Epigrammata dão a face diurna e a nocturna de Roma, desde a grandeza dos palácios e villas dos próceres, que sobranceiam a cidade, até às mansardas repulsivas dos pobres que alojam no topo das casae $\mathrm{e}$ são expelidos para os arcos de uma ponte, com o cortejo inominável de trastes miserandos. Vão desde a face austera ou benigna dos patrícios

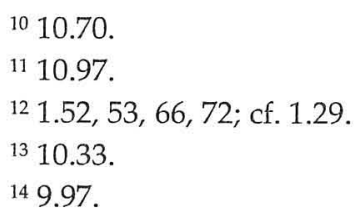


abonados até à caricatura impiedosa das velhas desdentadas ou carecas, as meretrizes de alto e de baixo nível, os beijoqueiros, os caçadores de heranças, os médicos emproados e os juristas palavrosos. "De que te servem os vãos joguetes de um mísero papel? / Lê estes versos, dos quais a vida poderia dizer: 'É meu haver deveras.' / Não acharás aqui Centauros nem Górgones nem Harpias. / A minha poesia tem sabor humano.»15

O sabor humano dos versos de Marcial, de «il poeta di Roma vivente», como Paoli o definiu - tem sido apreciado pelos estudiosos da literatura, da história e, até, de ciências tão distintas como a jurisprudência e a medicina; menor terá sido, no entanto, a consideração posta no homem que escreveu os Epigrammata. Pretensioso seria, em texto de mera "iniciação" como o presente, preencher lacunas deste tipo, que implicam uma destrinça (assaz problemática, muitas vezes), entre o eu de animação e o eu autobiográfico: mas importa observar que uma leitura atenta permitiria rastrear uma personalidade mais complexa que a desenvolvida, com simpatia ou com desdém, nos compêndios escolares ou em trabalhos monográficos. O coração de Marcial esteve sempre dividido entre o candor (que a saudade idealizava), a paz, a salubridade da terra natal e a sedução variegada, mas corrupta, do carrossel que a Urbe lhe oferecia. Triunfou, mau grado seu (mas onde há aí artista que rejeite a cópia de materiais que lhe proponham?), a atracção da Urbe - à custa, no entanto, de lacerações que lhe infelicitaram a existência. Elegância e rigor tornam clássica a sua expressão (o que contribui não pouco para redimir os próprios carmes obscenos) - e, no entanto, Marcial reconhece a debilidade de algumas das suas composições, porque prefere agradar aos convivas, que não aos cozinheiros. ${ }^{16}$ Efebos dulcerosos e meretrizes calejadas percorrem os seus versos, mas nenhum ateou a labareda que fizesse resplandecer a sua vida e a sua poesia. E, no entanto, Marcial amou os seus amigos com um fervor que poucos souberam retribuir e com uma veemência que não tem paralelo superior na Antiguidade: e não apenas os patrícios e os libertos, mas também os escravos e as crianças, que a todos envolve em real ternura. Marcial geme com a mesquinharia da sua vida de cliente, mas convictamente afirma a imortalidade da sua poesia. Marcial não é um histrião calculista e egocêntrico. O poeta confiou a um grande amigo, que como ele se chamava Marcial, o seu ideal de beatitude: «Os bens que

1510.4 .

169.81 . 
tornam a vida mais feliz, / ó Marcial, espelho de gentileza, ei-los quais são: / fazenda não granjeada à custa de suor, mas de uma herança; / um campo não ingrato, o lume sempre a arder; / querelas, jamais; a toga raras vezes; a paz no coração; / galhardia na força, saúde no arcaboiço; / uma franqueza acautelada, uma amizade assente na igualdade; / lhaneza no trato, a mesa despida de requinte; / a noite sem orgia, mas livre de cuidados; / um leito não austero, embora recatado; / um sono que abrevie a escuridão; / a vontade de ser o que se é, sem alimentar outras ambições; / o dia derradeiro, não o temer nem desejar.. ${ }^{17}$ Se percorrermos um a um os ítens desta enumeração, de admirável singeleza, descobriremos facilmente que a felicidade raras vezes se dignou morar com o poeta.

Trinta e quatro anos viveu Marcial em Roma, vergado, com crescente rebeldia, ao fadário de cliente, que o obrigava a levantar muito cedo e a enfrentar chuva e frio para ir saudar os seus patronos e assisti-los nas suas deslocações. Quando poderia escrever? Por fim, a sua obsessão era dormir: ${ }^{18}$ mas tinha Roma à cabeceira, ${ }^{19}$ e só na sua quinta nomentana lhe era dado repousar. ${ }^{20}$

A morte violenta de Domiciano acelerou o plano de regresso à terra natal. Ainda tentou cativar os príncipes Nerva e Trajano (este, hispano como ele); mas tinha bajulado de mais o caluus Nero para merecer a confiança dos novos imperadores, empenhados, para mais, em debelar a pública adulação. Baldados estes esforços, liquidou todos os seus bens e, com a viagem paga por Plínio-o-Moço, regressou.

Os seus compatrícios não festejaram Marcial com o calor que o poeta esperaria, antes teceram, por vezes, uma rede de intrigas à sua volta. Apenas uma viúva admiradora, Marcela, louvada pela pureza da sua dicção romana, lhe ofereceu uma quinta, rica de águas, de flores, de aves domésticas. Mas este pequeno paraíso não lhe apagava as memórias de Roma, a saudade dos amigos, das conversações, das bibliotecas, dos tipos facetos e actos caricatos que alimentavam a sua poesia. ${ }^{21}$ Se pudesse

\footnotetext{
17 10.47; cf. 1.55, 2.90.

18 10.74.12.

19 12.57.27.

20 12.57.27-28.

${ }^{21}$ Carta-prefácio do 1. 12.
} 
- ah, se pudesse! -, voltaria a Roma. Mas a Morte chegou primeiro e apagou aquele coração desencontrado.

A cinza lançada ao rio atinge, anónima e deslassada, a sua foz:22 e emudece. A faúlha, que a reanimara, mergulhou no grande mar, o Oceano: detrito extinto, para sempre. Assim, do teatro encenado, que forma perdura? O horizonte ambíguo, no segredo - remoto e inalcançável - que os vivos não sabem decifrar.

22 Salão se denomina o rio que corre em Bílbilis: mas o autor deste texto quis referir-se ao vizinho Tago, que Marcial cita orgulhosamente ao falar da sua terra e em outras ocasiões $(1.49 ; 4.55 ; 6.86 ; 7.88 ; 8.78 ; 10.17,65,78,96 ; 12.2)$. 